\title{
The relationship between depression, anxiety, and cardiovascular outcomes in patients with acute coronary syndromes
}

REVIEW

\author{
Jeff C Huffman' \\ Christopher M Celano' \\ James $L$ Januzzi ${ }^{2}$ \\ 'Department of Psychiatry, \\ ${ }^{2}$ Department of Cardiology, \\ Massachusetts General Hospital, \\ Boston, MA USA
}

This article was published in the following Dove Press journal:

Neuropsychiatric Disease and Treatment

3 May 2010

Number of times this article has been viewed
Correspondence: Jeff C Huffman

Department of Psychiatry, Massachusetts General Hospital, 55 Fruit Street/Blake II, Boston, MA, 02II4, USA

Tel +6177242910

Fax +6177249155

Email jhuffman@partners.org

\begin{abstract}
Depression and anxiety occur at high rates among patients suffering an acute coronary syndrome (ACS). Both depressive symptoms and anxiety appear to adversely affect in-hospital and long term cardiac outcomes of post-ACS patients, independent of traditional risk factors. Despite their high prevalence and serious impact, mood and anxiety symptoms go unrecognized and untreated in most ACS patients and such symptoms (rather than being transient reactions to ACS) persist for months and beyond. The mechanisms by which depression and anxiety are linked to these negative medical outcomes are likely a combination of the effects of these conditions on inflammation, catecholamines, heart rate variability, and endothelial function, along with effects on health-promoting behavior. Fortunately, standard treatments for these disorders appear to be safe, well-tolerated and efficacious in this population; indeed, selective serotonin reuptake inhibitors may actually improve cardiac outcomes. Future research goals include gaining a better understanding of the combined effects of depression and anxiety, as well as definitive prospective studies of the impact of treatment on cardiac outcomes. Clinically, protocols that allow for efficient and systematic screening, evaluation, and treatment for depression and anxiety in cardiac patients are critical to help patients avoid the devastating effects of these illnesses on quality of life and cardiac health.
\end{abstract}

Keywords: acute coronary syndrome, anxiety, anxiety disorders, depression, myocardial infarction, unstable angina

\section{Introduction}

Depression and anxiety are common among patients who have an acute coronary syndrome (ACS) or other major cardiovascular event. Despite their frequency, these psychiatric syndromes often go unrecognized and can persist for months to years, substantially impacting quality of life. ${ }^{1-4}$ Furthermore, both depression and anxiety have been independently associated with negative cardiac outcomes in patients with acute cardiac events and, indeed, across the spectrum of cardiac disease. ${ }^{5-8}$ Fortunately, safe and effective treatments exist for depression and anxiety disorders in these patients, ${ }^{9-11}$ and systematic evaluation of cardiac patients for psychiatric symptoms has the potential to substantially improve outcomes. ${ }^{12}$

In this review, we will examine the phenomenology of ACS and outline the prevalence and medical impact of depression and anxiety in patients with ACS and other forms of cardiovascular illness. We will discuss the mechanisms by which mood and anxiety symptoms may impair cardiac prognosis and will describe treatment considerations in this population. In the literature, depression in cardiac patients has been defined in several different ways, with some studies focusing on the formal syndrome of major 
depression and others focusing on elevated depressive symptoms on self-report measures. Similarly, though most studies of anxiety in heart disease have used self-report measures, there is increasing study of specific anxiety disorders among patients with cardiac illness. In this article, we will review the literature on both self-reported symptoms of depression and anxiety and the existing data on specific depressive and anxiety disorders.

\section{Acute coronary syndromes: an overview}

Cardiovascular disease is the number one cause of death in the world. ${ }^{13}$ Among patients with cardiovascular disease, unstable angina (UA) and myocardial infarction (MI) are severe, life-threatening conditions that represent sudden myocardial ischemia (loss of blood flow to the heart muscle, with loss of oxygen to cardiac cells). Both UA and MI are generally captured under the umbrella term ACS; this term represents a wide clinical spectrum of myocardial ischemia severity, ranging from UA (by definition, ischemia without myocardial injury) to MI, representing ischemia with resultant cell death (Figure 1).

Each year, more than one million Americans suffer an ACS. ${ }^{14}$ Risk factors for having cardiac disease, and ultimately an ACS, include gender (men are slightly more likely to have cardiac illness), age (men over 45 years and women over 55 years), family history of cardiovascular disease, and modifiable risk factors. ${ }^{14} \mathrm{ACS}$ is more common in men (eg, $58 \%$ of all ACS events occurred in men in 2005), though ACS prevalence in women approaches that of men in older age. ${ }^{14}$ Modifiable risk factors for an ACS include hypertension, hyperlipidemia, diabetes, sedentary lifestyle, and smoking. In addition to these risk factors, it has become increasingly clear that psychological factors, particularly depression and anxiety, may play an important and independent role in the development and propagation of cardiac disease. Further, some have begun to suggest that depression, in particular, be included among the list of classic cardiac risk factors given the strength of evidence linking this illness to cardiac outcomes. $^{15,16}$

Pathophysiologically, the most common cause for an ACS is the disruption of a previously nonsevere atherosclerotic plaque. Indeed, it is now recognized that the great majority of coronary atherosclerotic plaques that lead to ACS are typically relatively nonobstructive prior to the ACS, with a predisposition to rupture that is determined more by their intrinsic biology, than degree of protrusion into the coronary lumen. ${ }^{17}$
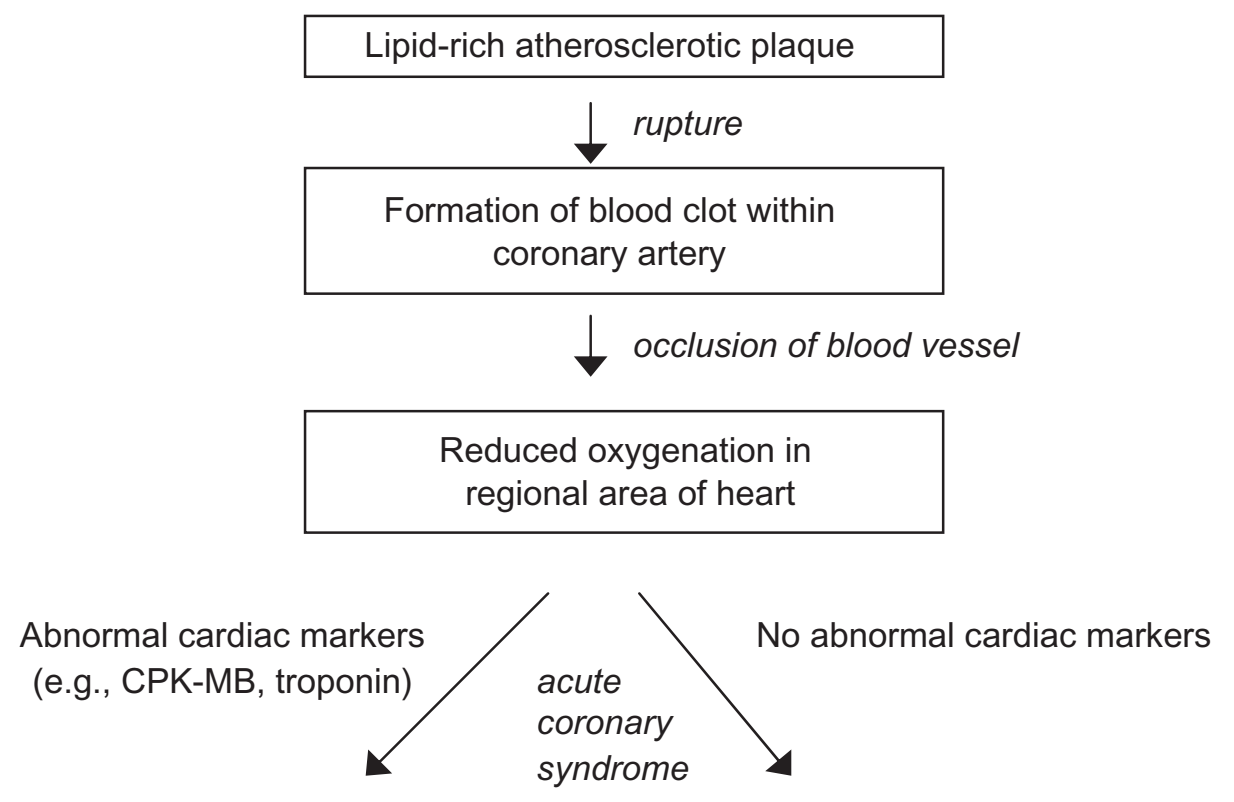

\section{Acute myocardial infarction}

\section{Unstable angina}

Figure I Pathophysiology of acute coronary syndrome. 
The characteristic "vulnerable" atherosclerotic plaque is one that has a rich lipid core (typically filled with necrotic, highly inflammatory debris), a large number of inflammatory cells (such as macrophages), a paucity of fibroblasts, and a relatively thin fibrous cap separating the plaque contents from the blood. ${ }^{17}$ In the context of a trigger, biological or physiological, the thin fibrous cap may rupture, leading to a cascade of events ranging from an asymptomatic cardiac event to sudden cardiac death.

In the context of plaque rupture, a series of inflammatory and platelet-related events lead to the formation of a thrombus, a blood clot, on the surface of the plaque, which may lead to occlusion of the coronary artery. ${ }^{18}$ Factors that determine this process include both the size and severity of the plaque rupture, as well as the vigor of the biological response to plaque rupture, including severity of platelet response and coagulation activation.

If the coronary thrombosis is significant enough, blood flow to that area of the heart is either reduced or blocked and myocardial ischemia results. Moreover, a substantial degree of myocardial ischemia in the context of ACS is not only due to occlusion of the epicardial coronary vessel, but also to downstream embolization of platelet-rich debris to the resistance microvasculature. ${ }^{19}$ In the setting of acute myocardial ischemia, classic signs and symptoms in men that may follow include chest heaviness that may radiate to the jaw or arm, diaphoresis, shortness of breath, and lightheadedness. Such symptoms may be less common in certain important populations, such as women and the elderly.

Diagnostically, patients with suspected ACS are evaluated with 12-lead electrocardiography (ECG). Diagnostic changes on ECG include depression or elevation of the ST-segments; the presence of either of these findings identifies a patient with severe coronary ischemia (ST-depression) or frank myocardial injury (ST-elevation). If the ACS leads to cardiac cell death, typically detected using sensitive tests for myocardial cell death (eg, serum troponin) then, by definition, it is an MI. In addition to being useful for diagnosis of MI, serum troponins also predict the risk for recurrent MI, as well as death. ${ }^{20}$ Accordingly, troponin elevation in the setting of an ACS identifies a population of patients that are typically managed in a more aggressive fashion clinically.

Typical acute treatments for ACS include oxygen, aspirin, beta-adrenergic blocking agents, high dose lipid-lowering agents, anticoagulants such as heparin, as well as nitroglycerin, and/or morphine sulfate for ongoing symptoms. More aggressive antithrombotic drugs such as clopidogrel (an oral antiplatelet agent) and/or platelet glycoprotein antagonists are widely used in this setting as well.

Goals of acute treatment are to eradicate symptoms, normalize electrocardiogram findings, and prevent complications. In addition to medication treatment, patients (especially those suffering a myocardial infarction with ST-segment elevation seen on the ECG) will undergo reperfusion treatment. Most commonly, the patient will undergo urgent/ emergent cardiac catheterization with coronary angiography, to identify areas of stenosis within the coronary artery system. These narrowed areas may then be dilated using balloon angioplasty, most commonly with adjunctive placement of a coronary stent. In the absence of available catheterization facilities, reperfusion can also be achieved using fibrinolytic agents, medications that may dissolve the intracoronary thrombosis, although the success of fibrinolysis is significantly lower than angioplasty and stenting. ${ }^{21}$

Once the symptoms of ACS have acutely subsided, important medication interventions to reduce risk of future complications and recurrence include the use of a wide array of medications, including beta-blockers, angiotensin-converting enzyme inhibitors, cholesterol-lowering agents, and antiplatelet agents (aspirin, clopidogrel). Lifestyle and risk factor modification is also essential.

\section{Depression and anxiety in patients with acute cardiac disease}

Among patients with cardiac disease, depression is common, persistent, and under recognized. The syndrome of major depression (Table 1) is present in approximately $15 \%$ of patients with cardiac disease, ${ }^{22}$ including those suffering ACS. ${ }^{23,24}$ Such a rate is substantially higher than that seen in the general population $(4 \% \text { to } 5 \%)^{25}$ or primary care patients ( $8 \%$ to $10 \%) .{ }^{26}$ Though some cardiac illnesses may have associated impairments of appetite, concentration, sleep, and energy, true depression (with persistent depressed mood or anhedonia) is not a normal consequence of cardiac disease.

Rather than being a transient reaction to having cardiac disease, depression in cardiac patients is often both chronic and recurrent. ${ }^{27,28}$ For example, the large Sertraline Antidepressant Heart Attack Randomized Trial (SADHART) trial ${ }^{27}$ found that, among ACS patients who entered the hospital with major depression, $94 \%$ of such patients had been depressed for over one month, $61 \%$ had been depressed for over six months and more than half had a prior major depressive episode. Furthermore, depressive symptoms are not transient after myocardial infarction, but instead persist if untreated. Two studies have found that 
Table I Criteria for a major depressive episode

A. Five (or more) of the following symptoms have been present most of the day, nearly every day, during the same two-week period; at least one of the symptoms is either depressed mood or loss of interest or pleasure:

I) depressed mood

2) markedly diminished interest or pleasure in all, or almost all, activities

3) decrease or increase in appetite, or significant weight loss when not dieting or weight gain (eg, a change of more than $5 \%$ of body weight in a month)

4) insomnia or hypersomnia

5) psychomotor agitation or retardation (observable by others, not merely subjective feelings of restlessness or being slowed down)

6) fatigue or loss of energy

7) feelings of worthlessness or excessive or inappropriate guilt (not merely self-reproach or guilt about being sick)

8) diminished ability to think or concentrate, or indecisiveness

9) recurrent thoughts of death or suicidal ideation

B. The symptoms cause clinically significant distress or impairment in social, occupational, or other important areas of functioning.

C. The symptoms are not due to the direct physiological effects of a substance (eg, a drug of abuse, a medication), a general medical condition (eg, hypothyroidism), and are not better accounted for by bereavement.

Note: Adapted with permission from American Psychiatric Association. Diagnostic and Statistical Manual of Mental Disorders. 4th ed. Washington DC: American Psychiatric Press, 1994.

depressive symptoms are essentially stable over the year following MI, with little reduction of symptoms over this period in untreated patients. ${ }^{3,29}$ Despite the frequency and persistence of depression in this cohort, it often goes unrecognized and untreated in the vast majority of patients suffering ACS. A pair of studies on acute cardiac units found that front-line clinicians were unable to identify depression in their post-MI patients, ${ }^{2,4}$ and rates of depression treatment in this setting have been less than $15 \% .^{30,31}$

Anxiety is also common among patients with acute cardiovascular disease. Elevated levels of self-reported anxiety are present in $20 \%$ to $50 \%$ of patients following acute $\mathrm{MI},{ }^{1,32-34}$ with up to one quarter experiencing symptoms of anxiety at least as intense as the average inpatient on a psychiatric unit. ${ }^{35}$ Anxiety often persists after such cardiac events and, among patients with anxiety shortly after ACS, many have clinically significant anxiety up to 2 years later. ${ }^{1,36,37}$ The finding that patients with stable coronary heart disease have higher levels of anxiety than the general population, with prevalence rates ranging from $16 \%$ to $42 \%$, is further evidence of the pervasive nature of anxiety in coronary heart disease patients. ${ }^{6,38-40}$
In addition to elevated levels of overall anxiety as measured on anxiety scales, formal anxiety disorders are more common in cardiac patients than in the general population. One cross-sectional study utilizing semi-structured diagnostic interviews found that $36 \%$ of patients met criteria for an anxiety disorder at the time of evaluation and $45 \%$ had a lifetime history of an anxiety disorder. ${ }^{41}$ Generalized anxiety disorder is present in up to $24 \%$ of patients with cardiac disease, ${ }^{6,41,42}$ and panic disorder also occurs at substantially elevated rates among patients with cardiovascular disease, with 5\% to 50\% of cardiac patients having active panic disorder. ${ }^{41,43-45}$

As with depression, clinically significant anxiety in post-ACS patients often goes unrecognized and untreated by front-line clinicians on cardiac inpatient units. ${ }^{2}$ Follow-up of patients with these symptoms is equally limited; in one study, roughly one third of patients who had elevated anxiety following an ACS were questioned about these symptoms by their medical clinicians over the next year. ${ }^{1}$

\section{Links between depression, anxiety, and negative cardiac outcomes among patients suffering acute ischemic events}

There is substantial evidence to suggest that depression is independently associated with negative cardiac outcomes across the spectrum of cardiac disease. Depression in healthy persons without cardiac disease has been associated with the development of coronary artery disease. The Johns Hopkins Precursor study followed male medical students for 40 years and found depression to independently predict the subsequent development of cardiac disease and MI. ${ }^{46}$ Since that time, there have been numerous studies of healthy men and women linking depression to the onset of cardiac illness; a meta-analysis of this population found that depression was associated with a $60 \%$ increase in cardiac disease. ${ }^{47}$

Among patients with existing cardiac disease, depression has been associated with progression of the illness. Patients found to have depression when diagnosed with coronary artery disease at cardiac catheterization are more likely to have acute cardiovascular/ischemic events than nondepressed patients ${ }^{48}$ and hypertensive patients with depression more likely to die of their cardiac disease. ${ }^{49}$

Finally, and most strikingly, patients with depression in the setting of acute myocardial ischemia (ACS) have substantially impaired medical/cardiac outcomes compared to those without depression. Specifically, post-MI depression is associated with poor health-related quality of life, recurrent 
cardiac events, and mortality, independent of other medical and demographic characteristics. ${ }^{24,50,51}$ These links appear to exist either when depression is measured by self-report or by a structured clinical interview. ${ }^{5}$ A 2004 meta-analysis of 22 studies that included over 6000 patients found that the uncorrected relative risks of recurrent cardiac events and cardiac mortality in the year following MI were 2.0 and 2.6 in patients with depression in the post-MI period compared to those without depression. ${ }^{24}$

Depressive symptoms in the post-ACS period can have far reaching consequences. A recent longitudinal study of postACS depression found that baseline depression severity a few weeks after ACS was a strong and independent risk factor for cardiac mortality approximately 7 years after the index event. ${ }^{52}$ Findings from this study and others indicate that ACS patients whose depression is resistant to standard treatments appear to be at highest risk of suffering adverse cardiac outcomes. ${ }^{52-54}$ It is unclear whether this is because the depression persists or whether this is a separate subtype of depression.

In addition to the long term effects of post-ACS depression, it appears that depression may also have immediate detrimental effects among those admitted to the hospital with acute myocardial ischemia. In this regard, at least two studies have found that MI patients who enter the hospital with an ongoing major depressive episode are more likely to have an in-hospital cardiac complication. ${ }^{31,55}$ Though most studies of ACS patients have primarily evaluated depression after MI, depression in the setting of UA has also been specifically associated with cardiac morbidity and mortality. ${ }^{23}$

Anxiety also appears to be linked to negative cardiac outcomes across the spectrum of cardiac disease. Persons with elevated anxiety have higher rates of subsequent development of coronary heart disease than nonanxious persons, independent of other risk factors. Indeed, anxiety may be more strongly associated with the onset of cardiac disease than depression. ${ }^{8}$ In particular, worry is a component of anxiety that appears to be especially associated with cardiac disease. ${ }^{56,57}$ Among patients with acute cardiovascular disease, the population of patients most vulnerable to catastrophic cardiac events and complications, several studies have found that elevated anxiety after MI has been independently associated with inhospital cardiac complications. ${ }^{58-60}$ Furthermore, though prior studies found no such association, ${ }^{34,61}$ multiple recent studies have also found that anxiety following MI is associated with longer-term cardiac complications and mortality. ${ }^{1,6,62}$ These studies include a recent well-designed study by Frasure-Smith and colleagues ${ }^{6}$ finding that generalized anxiety disorder (GAD) in the setting of coronary artery disease was associated with 2 year major adverse cardiac events, independent of other patient characteristics and a study by Strik and coworkers ${ }^{62}$ finding that post-MI anxiety symptoms, independent of depression and medical characteristics, predicted recurrent cardiac events.

Do depression and anxiety have additive effects on cardiovascular outcomes among patients with myocardial ischemic events? There has been a relative paucity of studies in this area and thus far the results have been mixed. A recent analysis of data from the Women's Ischemia Syndrome Evaluation (WISE) study found that depressed women with higher levels of anxiety were more likely to have adverse cardiovascular events than depressed women with low anxiety. ${ }^{63}$ In contrast, the previously mentioned study by Frasure-Smith and colleagues ${ }^{6}$ found that both major depression and generalized anxiety disorder were associated with cardiac events, but that patients with both disorders were not at further elevated risk.

In sum, depression and anxiety appear to be independently associated with adverse cardiovascular outcomes among patients with ischemic heart disease; depression, in particular, appears to be clearly associated with cardiac events in both the short and long term.

\section{Potential mechanisms linking depression/anxiety and myocardial ischemia}

Given the substantial literature linking depression and anxiety with adverse cardiac events, there has been an increasing focus on determining the mechanisms by which these links may occur (Figure 2). Overall, there are two mechanistic categories that likely contribute to these associations: physiologic effects and behavioral effects. We will first discuss physiologic effects.

\section{Platelet activity and aggregation}

Platelet activity and aggregation are key components of acute myocardial ischemia and evidence of increased platelet activity and aggregation has been found in patients with depression. ${ }^{64-66}$ The connection between depression and platelet hyper-reactivity (and subsequent aggregation) may be mediated by serotonin. Serotonin is found both in the whole blood and in platelets and plays an essential role in platelet activation. When serotonin binds to 5-hydroxytryptamine-2 (5HT-2) receptors on platelets, it causes the release of procoagulant factors stored in the platelets and enhances platelet aggregation, leading to clot formation. In normal coronary arteries, thrombus formation and ischemia are prevented by serotonin's stimulation of 


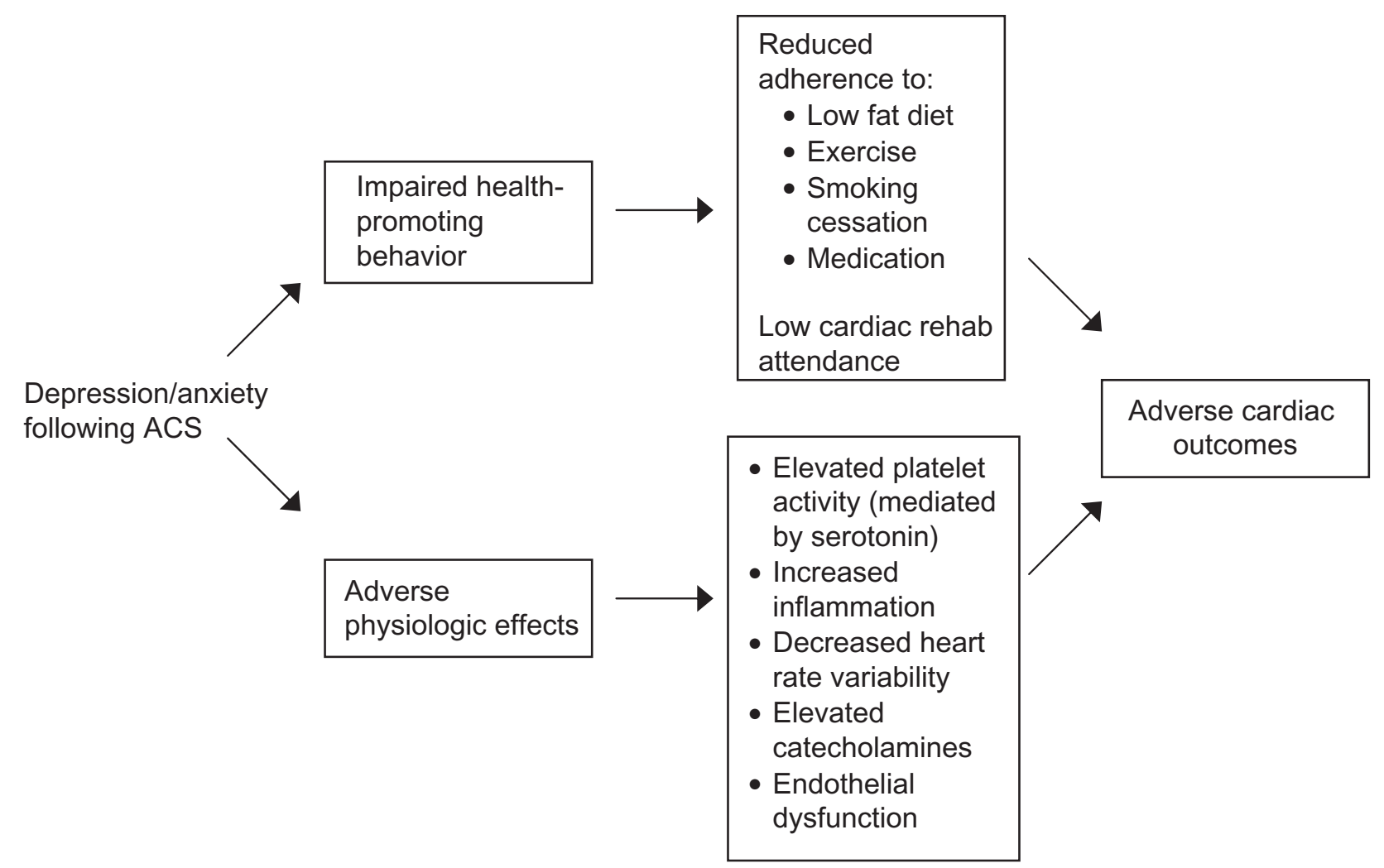

Figure 2 Putative mechanisms linking depression/anxiety and cardiac outcomes in acute coronary syndrome (ACS) patients.

the endothelium to release nitric oxide, which results in vasodilation in the area surrounding the clot. In atherosclerotic arteries, however, damage to the endothelium prevents the release of nitric oxide with the result that serotonin leads to vasoconstriction. ${ }^{67}$ Given this, it is not surprising that elevated serotonin blood levels have been associated with coronary artery disease and cardiac events. ${ }^{68}$

The serotonergic system has also been implicated in the pathogenesis of major depression. Although evidence is not conclusive, several researchers have found that patients with depression (with and without heart disease) have abnormalities in whole blood and platelet serotonin levels, ${ }^{69,70}$ increased platelet serotonin receptor concentrations, ${ }^{71,72}$ and abnormally low platelet serotonin transporter levels, ${ }^{73}$ all of which could lead to serotonin-linked platelet dysfunction and could provide a explanation for how depression could lead to adverse cardiovascular outcomes.

Less is known about the effects of anxiety on platelet aggregation and activity, but the available evidence suggests that serotonin may also mediate changes in platelets in anxious patients. Abnormalities in the serotonergic system have been implicated in the pathogenesis of anxiety disorders and patients with phobic anxiety have been found to have abnormalities in the coagulation and fibrinolytic system leading to a hypercoagulable state. ${ }^{74}$ Furthermore, abnormalities in serotonin blood levels, ${ }^{75}$ platelet serotonin transporters, ${ }^{76}$ and platelet intracellular calcium levels in response to stimulation $^{77}$ (increasing sensitivity to procoagulant factors) have been reported in patients with specific anxiety disorders. In addition to these mechanisms, acute stress has also been associated with platelet hyperactivity, increased blood viscosity, and hemoconcentration, ${ }^{78,79}$ potentially increasing the risk for thrombosis and other cardiovascular complications mediated through platelet hyperactivity and increased blood viscosity.

\section{Inflammation}

Inflammation appears to play a key role in the pathogenesis of acute ischemic events. Inflammatory cytokines such as tumor necrosis factor-alpha (TNF- $\alpha$ ) and interleukin-1 (IL-1) are actively involved in the pathogenesis of atherosclerosis, ${ }^{80,81}$ and elevations of inflammatory markers, especially C-reactive protein (CRP), are independently associated with mortality following ACS. ${ }^{80,82}$ Depression is similarly associated with elevations of other inflammatory markers (eg, IL-1, IL-6, and TNF- $\alpha$ ), ${ }^{83}$ and this proinflammatory state in depression may lead to development or propagation of myocardial ischemic events. 
As with platelet activation, there is less data on the links between anxiety and inflammation, but levels of circulating inflammatory markers are abnormal in persons with elevated anxiety. A large study of healthy adults found elevated levels of anxiety to be independently associated with abnormalities of multiple inflammatory markers, even after adjustment for multiple other factors. ${ }^{84}$ With regard to specific anxiety disorders, post-traumatic stress disorder (PTSD) has been associated with abnormal levels of inflammatory markers (eg, IL-1, IL-6, TNF- $\alpha$, and CRP) in both noncardiac and post-MI patients. ${ }^{85,86}$ In addition, women with diabetes who have phobic anxiety have higher levels of inflammatory cytokines,${ }^{87}$ and generalized anxiety disorder is associated with elevated levels of CRP among patients with cardiac disease. ${ }^{88}$

\section{Heart rate variability}

Heart rate variability (HRV), a measure of the beat-to-beat variability of the heart, involves a complex interplay between the sympathetic and parasympathetic nervous systems and their impact on the cardiac pacemaker. Decreased HRV in post-MI patients has been consistently associated with mortality, ${ }^{89}$ thought to be due in part to elevated risk of arrhythmia. ${ }^{90}$ Several studies have found clinical depression to be associated with diminished HRV, ${ }^{91}$ including studies of depressed cardiac patients, ${ }^{92,93}$ and given the relative risk of arrhythmic events among post-MI patients, depression may substantially increase risk of cardiac arrhythmic events in this vulnerable population. Likewise, anxiety has been associated with decreased HRV ${ }^{94}$ and both depression and anxiety in patients with implantable defibrillators has been linked to low HRV. ${ }^{95}$

\section{Elevated catecholamines}

Hyperactivity of the sympathetic nervous system leads to increased release of catecholamines in the periphery. This in turn leads to vasoconstriction, blood pressure elevation, platelet activation, and arrhythmia, all of which can have detrimental effects on cardiovascular stability. Depression is associated with sympathetic nervous system dysregulation, ${ }^{96,97}$ and, similarly, acute anxiety and chronic worry lead to sympathetic nervous system hyperactivity and autonomic dysregulation, ${ }^{98-100}$ providing another potential causative link between these disorders and adverse cardiac events.

\section{Endothelial dysfunction}

The endothelium is the critical, active layer of tissue between circulating blood and the vasculature and is a key regulator of vascular homeostasis. Endothelial dysfunction has a substantial impact on cardiovascular health. Indeed, endothelial dysfunction in patients with cardiovascular illness has been independently associated with increased rates of cardiac mortality. ${ }^{101-103}$ It is increasingly understood that depression is associated with abnormal function of the endothelium, with depressed patients having more abnormalities on specialized testing of the endothelium than patients who are nondepressed, independent of other factors. ${ }^{104,105}$ Endothelial dysfunction also has been reported in patients with elevated levels of anxiety, particularly in the elderly. ${ }^{106-108}$ Abnormal vascular function in the setting of depression or anxiety certainly could lead to adverse cardiovascular physiology and outcomes.

\section{Behavioral effects}

In addition to these physiologic effects, depression is associated with poor secondary prevention among patients who have had an acute ischemic event. Patients with post-MI depression, compared to MI patients who are not depressed, are less likely to follow a low fat diet, reduce their cholesterol, exercise, quit smoking, or reduce stress in their lives, all of which increase their risk for a recurrent cardiac event. ${ }^{109,110}$ In fact, in the large Heart and Soul study ${ }^{11}$ of patients with depression and coronary artery disease, an association between depressive symptoms and adverse cardiovascular events was largely explained by behavioral factors, especially physical inactivity. Patients suffering from anxiety or emotional distress following MI also have been found to have difficulty adhering to riskreducing behaviors such as easing stress, increasing socialization, improving diet, and ceasing to smoke. ${ }^{61,112}$ Finally, patients with depression or anxiety may be less likely to attend ${ }^{113,114}$ or complete ${ }^{115,116}$ cardiac rehabilitation programs where both their secondary prevention behaviors and their psychiatric symptoms could be addressed.

In sum, depression and anxiety have myriad effects on cardiovascular physiology via a variety of mechanisms and these effects likely play a role in the increased incidence of ischemic events in patients with these symptoms. Furthermore, the effects of depression and anxiety on health-promoting behavior clearly play a role in these patients' poor cardiac outcomes.

\section{Treatments for depression and anxiety in cardiac patients Antidepressants}

Antidepressants can be used to treat patients with depression and patients with formal anxiety disorders, such as 
generalized anxiety disorder, panic disorder, or post-traumatic stress disorder. In general, the older tricyclic antidepressants (eg, amitriptyline, nortriptyline) should be avoided in patients with cardiac illness. First, these agents have adverse cardiovascular side effects in this population including orthostatic hypotension as well as tachycardia due to anticholinergic effects. Furthermore, these agents can lengthen cardiac intervals (eg, QRS and QTc) and can be proarrhythmic in a subset of the population. ${ }^{117}$ In epidemiologic studies, prescription of tricyclic antidepressants has been associated with increased rates of subsequent MI compared to patients receiving selective serotonin reuptake inhibitors (SSRIs) or no treatment. ${ }^{118}$

In contrast, SSRIs appear to be safe and effective in cardiac populations. These agents can be used to treat depression and formal anxiety disorders (eg, generalized anxiety disorder, panic disorder) in cardiac patients. Though SSRIs can be associated with increased anxiety, insomnia, or restlessness during the first several days of treatment in some patients, these effects are generally mild. They do not commonly cause orthostasis, tachycardia, or other adverse cardiovascular effects, and are well-tolerated in this population. Small trials of SSRIs and other antidepressants have found these agents to be safe and to significantly reduce symptoms of depression in patients with ischemic heart disease. ${ }^{119,120}$

A larger study, the Canadian Cardiac Randomized Evaluation of Antidepressant and Psychotherapy Efficacy (CREATE) placebo-controlled trial of 284 depressed outpatients with coronary artery disease, found that citalopram was significantly more efficacious than placebo. ${ }^{28}$ Citalopram was well-tolerated in this study and was not associated with serious adverse events. Further, the multicenter SADHART randomized controlled trial of 369 post-ACS patients with major depressive disorder (MDD) found sertraline to be safe, well-tolerated, and efficacious in patients who began treatment approximately 1 month postACS. ${ }^{10}$ Furthermore, a post hoc analysis of the Enhancing Recovery in Coronary Heart Disease Patients (ENRICHD) trial (a trial of cognitive behavioral therapy (CBT) for postMI depression that had some patients taking antidepressants in both the experimental and control groups) found that patients receiving SSRIs had an over $40 \%$ reduction in the risk of cardiac mortality and reinfarction over a mean 29 month follow-up, compared to those not taking SSRIs. ${ }^{121}$ One potential mechanism by which SSRIs may reduce cardiac events may involve reduction of platelet activity, as treatment of depressed patients with SSRIs leads to decreased markers of platelet hyperactivity. ${ }^{65,122,123}$
Regarding other antidepressant agents, mirtazapine was studied in the randomized controlled Myocardial INfarction and Depression - Intervention Trial (MIND-IT) for patients with post-MI depression. The authors found that mirtazapine was safe, well-tolerated, and more efficacious than placebo over the 24 week trial. ${ }^{124}$ However, treatment with mirtazapine did not appear to impact cardiovascular outcomes, ${ }^{125}$ and some side effects of this agent (eg, weight gain, increased lipids) may relegate it to second-line status on patients with a history of myocardial ischemia. Finally, there is less evidence for the use of mirtazapine for anxiety disorders compared to the SSRIs.

Bupropion, while relatively unstudied for depression in patients with cardiac illness, has been studied in post-MI patients as an aid to smoking cessation. These studies found this agent to be safe and well-tolerated in this subset of patients (though it can cause anxiety, restlessness, or insomnia) and it has not been associated with increased rates of serious cardiovascular side effects. ${ }^{126}$ Therefore bupropion may be indicated in depressed cardiac patients who wish to quit smoking. Other antidepressants, such as venlafaxine and duloxetine, have not been well-studied in cardiac populations, though venlafaxine is known to have dose-dependent increases in blood pressure associated with its use. ${ }^{127}$

In sum, the SSRIs are well-studied agents for depression in patients with cardiac disease, are safe and efficacious in this population, can also be used for patients with anxiety disorders, and may be associated with decreased rates of adverse cardiac outcomes. Other antidepressants can be used under specific circumstances, though tricyclic antidepressants are generally not recommended.

\section{Benzodiazepines}

Benzodiazepines are effective in the reduction of acute anxiety and are effective in the treatment of some anxiety disorders (eg, panic disorder). These agents are rapidly effective and are well-used in patients with ongoing or recent myocardial ischemia for whom anxiety is leading to elevated heart rate, blood pressure, or other physiologic difficulties. These agents have several beneficial physiologic effects including acutely lowering catecholamine levels and decreasing coronary vascular resistance. ${ }^{11,128,129}$ However, there are several caveats with the use of these agents: they can be associated with increased risk of falls, sedation, respiratory depression, and physiologic dependence, ${ }^{130}$ and they do not treat comorbid depressive symptoms. Despite these caveats, these rapidly-acting anxiolytics can be substantially effective among patients with ischemic heart disease and ongoing anxiety, ${ }^{131}$ though 
for patients with depression or formal anxiety disorders, antidepressants are often the treatment of choice.

\section{Psychotherapy}

Psychotherapeutic interventions are appealing for cardiac patients because of their lack of somatic side effects. In addition, these interventions can be individualized to focus on a given patient's specific difficulties. Specific forms of psychotherapy have been studied in cardiac patients. The largest trial of psychotherapy in post-MI patients, the previously mentioned ENRICHD trial of 2481 patients, ${ }^{9}$ found that treatment with CBT significantly reduced depressive symptoms and improved quality of life among post-MI patients, though it did not (in contrast to antidepressants) improve cardiac outcomes. The CREATE trial, in addition to studying citalopram, also utilized an evidence-based treatment called interpersonal psychotherapy (IPT), but found it did not improve depressive symptoms compared to an active control. ${ }^{28}$ To our knowledge, there has not been a psychotherapeutic intervention for anxiety in cardiac patients, though CBT has been used to treat a wide variety of anxiety disorders in other populations. ${ }^{132}$ Finally, a variety of other supportive and psychotherapeutic interventions have been used in patients with cardiovascular disease for a variety of conditions and though the studies of many of these interventions have been less rigorous than those listed above, they appear to improve outcomes. ${ }^{133}$

Overall, psychotherapy can be effective for cardiac patients with depression or anxiety, though it may have less efficacy or impact on medical outcomes than treatment with antidepressants. A further pragmatic difficulty with psychotherapy is that such therapy, particularly evidencebased forms of treatment, can be difficult to source, especially in areas without nearby academic centers.

\section{Exercise and cardiac rehabilitation}

Exercise is an effective antidepressant, ${ }^{134}$ is associated with reduced anxiety, ${ }^{135}$ and has substantial cardiovascular benefit. A pair of trials of exercise (30 minutes of continuous walking/jogging to reach a target heart rate, three times per week for 16 weeks) in depressed patients found that regular exercise was as effective as sertraline in the treatment of depression. ${ }^{134,136}$ Follow-up results from the first trial, six months after the end of the study, found depression improvements among patients in the exercise group to be sustained longer than in those receiving antidepressants. ${ }^{137} \mathrm{In}$ addition, cardiac rehabilitation programs can provide many services that are helpful to cardiac patients with depression, from ongoing depression evaluation, to social support, to specific interventions for cardiovascular health. Therefore, both of these interventions can be tremendously helpful for cardiac patients with psychological distress.

However, cardiac patients with depression are less likely to exercise than their nondepressed counterparts ${ }^{110}$ and, as noted, are less likely to attend and complete cardiac rehabilitation programs. ${ }^{114,116}$ Anxiety also appears to reduce participation in these programs. ${ }^{115}$ Clinically, we often find that improving patients' depression, anxiety, and distress initially with medication or psychotherapy is necessary before they are willing and able to participate in exercise or cardiac rehabilitation.

\section{Impact of cardiovascular medications on mood and anxiety symptoms}

Patients with cardiac disease, especially those with a history of ischemic events, may be prescribed multiple medications. In general, many commonly prescribed agents, including aspirin, clopidogrel, warfarin, angiotensin-converting enzyme inhibitors, and nitrates are not associated with substantial psychiatric effects. ${ }^{138}$ Though low cholesterol has been associated with increased rates of depression, aggression, and suicidality in some trials, ${ }^{139-142}$ this link has also been refuted in several studies. Furthermore, lowering serum cholesterol does not appear to increase the risk of depression or suicidal behavior $^{143}$ and studies of lipid-lowering agents such as HMG-CoA reductase inhibitors ('statins') have not found any association between these agents and mood symptoms, aggression, or changes in cognition. ${ }^{144,145}$

Finally, the association between beta-blockers and depression has long been controversial. A number of case reports and several small studies (that sometimes did not control for some important covariables) found associations between propranolol and the onset of depression, ${ }^{146,147}$ however, a larger prospective controlled study and comprehensive review of the literature on propranolol found no association between this agent and depression. ${ }^{148,149}$ When expanded to include other beta-blockers, the majority of studies and reviews, including a large 2002 meta-analysis, ${ }^{150}$ found no association with depression, though there is some association between beta-blockers and fatigue. On the other hand, beta-blockers, specifically propranolol, have been found to be effective in the treatment of anxiety and aggression. ${ }^{151,152}$ In sum, the relationship between propranolol and depression is equivocal. There is probably no association between beta-blockers and depression for the other agents in this class, though idiosyncratic reactions are always possible. 
In contrast, propranolol can be used as a therapeutic agent for cardiac patients with anxiety or aggression.

\section{Conclusion}

Depression and anxiety among patients with acute myocardial ischemia are highly prevalent and independently associated with adverse cardiovascular outcomes, including mortality. At this point, there is little doubt that addressing these conditions is critical in cardiac patients, but there remain a number of research and clinical steps to bridge the gap between this knowledge and patients receiving optimal care.

With respect to future research, it will be important to learn more about the combined effects of depression and anxiety on cardiac outcomes. Another important goal is the identification of subsets of cardiac patients for whom early and aggressive treatment of depression and anxiety is particularly critical. In addition, a better understanding of the mechanisms by which these psychiatric symptoms impair cardiovascular health may allow the development of mechanism-specific treatments. Finally, large prospective studies, if feasible, of existing treatments of depression and anxiety (eg, SSRIs) to determine whether cardiac outcomes improve as a result of their use would provide highly valuable information about the medical impact of these treatments.

Clinically, it is vital to find ways to help front-line practitioners to systematically identify depression and anxiety among their patients with cardiovascular disease. Likewise, it is necessary to develop infrastructure such that identified patients receive basic, but critical, treatments for these disorders. One future step that could combine clinical care and research is further investigation of care management models. These models of assessment and treatment utilize a care manager to efficiently identify patients with depression and anxiety. The care manager then coordinates treatment between patient, primary care physician, and consulting psychiatrist in a longitudinal manner. Such models have been used in outpatient medical settings and have been found to significantly improve depression and anxiety outcomes in a cost-effective manner. ${ }^{153-156}$ Most recently, such a model led to improved outcomes in depressed patients undergoing cardiac surgery. ${ }^{157}$ Patients with a history of acute cardiovascular disease, such as ACS, represent a population who may most benefit from care management programs, given the strong link between depression/anxiety and medical outcomes.

\section{Disclosures}

The authors report no conflicts of interest relevant to this research.

\section{References}

1. Grace SL, Abbey SE, Irvine J, Shnek ZM, Stewart DE. Prospective examination of anxiety persistence and its relationship to cardiac symptoms and recurrent cardiac events. Psychother Psychosom. 2004;73:344-352.

2. Huffman JC, Smith FA, Blais MA, Beiser ME, Januzzi JL, Fricchione GL. Recognition and treatment of depression and anxiety in patients with acute myocardial infarction. Am J Cardiol. 2006;98:319-324.

3. Kaptein KI, de Jonge P, van den Brink RH, Korf J. Course of depressive symptoms after myocardial infarction and cardiac prognosis: a latent class analysis. Psychosom Med. 2006;68:662-668.

4. Ziegelstein RC, Kim SY, Kao D, et al. Can doctors and nurses recognize depression in patients hospitalized with an acute myocardial infarction in the absence of formal screening? Psychosom Med. 2005;67:393-397.

5. Barth J, Schumacher M, Herrmann-Lingen C. Depression as a risk factor for mortality in patients with coronary heart disease: a meta-analysis. Psychosom Med. 2004;66:802-813.

6. Frasure-Smith N, Lesperance F. Depression and anxiety as predictors of 2-year cardiac events in patients with stable coronary artery disease. Arch Gen Psychiatry. 2008;65:62-71.

7. Frasure-Smith N, Lesperance F, Talajic M. Depression and 18-month prognosis after myocardial infarction. Circulation. 1995;91: 999-1005.

8. Kubzansky LD, Kawachi I. Going to the heart of the matter: do negative emotions cause coronary heart disease? J Psychosom Res. 2000;48:323-337.

9. Berkman LF, Blumenthal J, Burg M, et al. Effects of treating depression and low perceived social support on clinical events after myocardial infarction: the Enhancing Recovery in Coronary Heart Disease Patients (ENRICHD) Randomized Trial. JAMA. 2003;289:3106-3116.

10. Glassman AH, O'Connor CM, Califf RM, et al. Sertraline treatment of major depression in patients with acute MI or unstable angina. JAMA. 2002;288:701-709.

11. Huffman JC, Stern TA. The use of benzodiazepines in the treatment of chest pain: a review of the literature. J Emerg Med. 2003;25: 427-437.

12. Gilbody S, Sheldon T, House A. Screening and case-finding instruments for depression: a meta-analysis. CMAJ. 2008;178:997-1003.

13. World Health Organization. The World Health Report 2004-changing history. 2004. Available at http://www.who.int/whr/2004/annex/topic/ en/annex_2_en.pdf. Accessed on January 10, 2010.

14. Lloyd-Jones D, Adams RJ, Brown TM, et al. Heart Disease and Stroke Statistics-2010 Update. A report from the American Heart Association. Circulation. 2010;121:e46-e215.

15. Wulsin LR. Is depression a major risk factor for coronary disease? A systematic review of the epidemiologic evidence. Harv Rev Psychiatry. 2004;12:79-93.

16. Carney RM, Freedland KE, Sheps DS. Depression is a risk factor for mortality in coronary heart disease. Psychosom Med. 2004;66: 799-801.

17. Fishbein MC. The vulnerable and unstable atherosclerotic plaque. Cardiovasc Pathol. 2010;19:6-11.

18. Hansson GK. Inflammation, atherosclerosis, and coronary artery disease. $N$ Engl J Med. 2005;352:1685-1695.

19. Yamada DM, Topol EJ. Importance of microembolization and inflammation in atherosclerotic heart disease. Am Heart J. 2000; 140:S90-S102.

20. Morrow DA, Cannon CP, Rifai N, et al. Ability of minor elevations of troponins I and $\mathrm{T}$ to predict benefit from an early invasive strategy in patients with unstable angina and non-ST elevation myocardial infarction: results from a randomized trial. JAMA. 2001;286:2405-2412.

21. Hsu LF, Mak KH, Lau KW, et al. Clinical outcomes of patients with diabetes mellitus and acute myocardial infarction treated with primary angioplasty or fibrinolysis. Heart. 2002;88:260-265.

22. Rudisch B, Nemeroff CB. Epidemiology of comorbid coronary artery disease and depression. Biol Psychiatry. 2003;54:227-240. 
23. Lesperance F, Frasure-Smith N, Juneau M, Theroux P. Depression and 1-year prognosis in unstable angina. Arch Intern Med. 2000;160: 1354-1360.

24. van Melle JP, de Jonge P, Spijkerman TA, et al. Prognostic association of depression following myocardial infarction with mortality and cardiovascular events: a meta-analysis. Psychosom Med. 2004;66:814-822.

25. Narrow WE, Rae DS, Robins LN, Regier DA. Revised prevalence estimates of mental disorders in the United States: using a clinical significance criterion to reconcile 2 surveys' estimates. Arch Gen Psychiatry. 2002;59:115-123.

26. Valenstein M, Vijan S, Zeber JE, Boehm K, Buttar A. The cost-utility of screening for depression in primary care. Ann Intern Med. 2001;134:345-360.

27. Glassman AH, Bigger JT, Gaffney M, Shapiro PA, Swenson JR. Onset of major depression associated with acute coronary syndromes: relationship of onset, major depressive disorder history, and episode severity to sertraline benefit. Arch Gen Psychiatry. 2006;63:283-288.

28. Lesperance F, Frasure-Smith N, Koszycki D, et al. Effects of citalopram and interpersonal psychotherapy on depression in patients with coronary artery disease: the Canadian Cardiac Randomized Evaluation of Antidepressant and Psychotherapy Efficacy (CREATE) trial. JAMA. 2007;297:367-379.

29. Martens EJ, Smith OR, Winter J, Denollet J, Pedersen SS. Cardiac history, prior depression and personality predict course of depressive symptoms after myocardial infarction. Psychol Med. 2008;38:257-264.

30. Frasure-Smith N, Lesperance F, Talajic M. Depression following myocardial infarction. Impact on 6-month survival. JAMA. 1993; 270:1819-1825.

31. Huffman JC, Smith FA, Blais MA, Taylor AM, Januzzi JL, Fricchione GL. Pre-existing major depression predicts in-hospital cardiac complications after acute myocardial infarction. Psychosomatics. 2008;49:309-316.

32. Hanssen TA, Nordrehaug JE, Eide GE, Bjelland I, Rokne B. Anxiety and depression after acute myocardial infarction: an 18-month followup study with repeated measures and comparison with a reference population. Eur J Cardiovasc Prev Rehabil. 2009;16:651-659.

33. Januzzi JL Jr, Stern TA, Pasternak RC, DeSanctis RW. The influence of anxiety and depression on outcomes of patients with coronary artery disease. Arch Intern Med. 2000;160:1913-1921.

34. Lane D, Carroll D, Ring C, Beevers DG, Lip GY. Mortality and quality of life 12 months after myocardial infarction: effects of depression and anxiety. Psychosom Med. 2001;63:221-230.

35. Crowe JM, Runions J, Ebbesen LS, Oldridge NB, Streiner DL. Anxiety and depression after acute myocardial infarction. Heart Lung. 1996;25:98-107.

36. Pedersen SS, Smith OR, De Vries J, Appels A, Denollet J. Course of anxiety symptoms over an 18-month period in exhausted patients post percutaneous coronary intervention. Psychosom Med. 2008;70:349-355.

37. Murphy BM, Elliott PC, Worcester MU, et al. Trajectories and predictors of anxiety and depression in women during the 12 months following an acute cardiac event. Br J Health Psychol. 2008;13:135-153.

38. Doering LV, Moser DK, Riegel B, et al. Persistent comorbid symptoms of depression and anxiety predict mortality in heart disease. Int J Cardiol. 2009.

39. Fan AZ, Strine TW, Jiles R, Mokdad AH. Depression and anxiety associated with cardiovascular disease among persons aged 45 years and older in 38 states of the United States, 2006. Prev Med. 2008;46:445-450.

40. Rothenbacher D, Hahmann H, Wusten B, Koenig W, Brenner H. Symptoms of anxiety and depression in patients with stable coronary heart disease: prognostic value and consideration of pathogenetic links. Eur J Cardiovasc Prev Rehabil. 2007;14:547-554.

41. Todaro JF, Shen BJ, Raffa SD, Tilkemeier PL, Niaura R. Prevalence of anxiety disorders in men and women with established coronary heart disease. J Cardiopulm Rehabil Prev. 2007;27:86-91.

42. Bankier B, Januzzi JL, Littman AB. The high prevalence of multiple psychiatric disorders in stable outpatients with coronary heart disease. Psychosom Med. 2004;66:645-650.
43. Muller-Tasch T, Frankenstein L, Holzapfel N, et al. Panic disorder in patients with chronic heart failure. J Psychosom Res. 2008;64: 299-303.

44. Huffman JC, Pollack MH. Predicting panic disorder among patients with chest pain: an analysis of the literature. Psychosomatics. 2003;44: 222-236.

45. Fleet R, Lavoie K, Beitman BD. Is panic disorder associated with coronary artery disease? A critical review of the literature. J Psychosom Res. 2000;48:347-356.

46. Ford DE, Mead LA, Chang PP, Cooper-Patrick L, Wang NY, Klag MJ. Depression is a risk factor for coronary artery disease in men: the precursors study. Arch Intern Med. 1998;158:1422-1426.

47. Wulsin LR, Singal BM. Do depressive symptoms increase the risk for the onset of coronary disease? A systematic quantitative review. Psychosom Med. 2003;65:201-210.

48. Carney RM, Rich MW, Freedland KE, et al. Major depressive disorder predicts cardiac events in patients with coronary artery disease. Psychosom Med. 1988;50:627-633.

49. Axon RN, Zhao Y, Egede LE. Association of depressive symptoms with all-cause and ischemic heart disease mortality in adults with self-reported hypertension. Am J Hypertens. 2010;23:30-37.

50. Carney RM, Freedland KE. Depression, mortality, and medical morbidity in patients with coronary heart disease. Biol Psychiatry. 2003;54:241-247.

51. de Jonge P, Spijkerman TA, van den Brink RH, Ormel J. Depression after myocardial infarction is a risk factor for declining health related quality of life and increased disability and cardiac complaints at 12 months. Heart. 2006;92:32-39.

52. Glassman AH, Bigger JT Jr, Gaffney M. Psychiatric characteristics associated with long-term mortality among 361 patients having an acute coronary syndrome and major depression: seven-year follow-up of SADHART participants. Arch Gen Psychiatry. 2009;66:10221029.

53. Carney RM, Freedland KE. Treatment-resistant depression and mortality after acute coronary syndrome. Am J Psychiatry. 2009;166:410-417.

54. de Jonge P, Honig A, van Melle JP, et al. Nonresponse to treatment for depression following myocardial infarction: association with subsequent cardiac events. Am J Psychiatry. 2007;164:1371-1378.

55. Dickens C, McGowan L, Percival C, et al. Association between depressive episode before first myocardial infarction and worse cardiac failure following infarction. Psychosomatics. 2005;46:523-528.

56. Kubzansky LD, Davidson KW, Rozanski A. The clinical impact of negative psychological states: expanding the spectrum of risk for coronary artery disease. Psychosom Med. 2005;67 Suppl 1:S10-S14

57. Kubzansky LD, Kawachi I, Spiro A 3rd, Weiss ST, Vokonas PS, Sparrow D. Is worrying bad for your heart? A prospective study of worry and coronary heart disease in the Normative Aging Study. Circulation. 1997;95:818-824.

58. Huffman JC, Smith FA, Blais MA, Januzzi JL, Fricchione GL. Anxiety, independent of depressive symptoms, is associated with in-hospital cardiac complications after acute myocardial infarction. J Psychosom Res. 2008;65:557-563.

59. Moser DK, Dracup K. Is anxiety early after myocardial infarction associated with subsequent ischemic and arrhythmic events? Psychosom Med. 1996;58:395-401.

60. Moser DK, Riegel B, McKinley S, Doering LV, An K, Sheahan S. Impact of anxiety and perceived control on in-hospital complications after acute myocardial infarction. Psychosom Med. 2007;69:1016.

61. Mayou RA, Gill D, Thompson DR, et al. Depression and anxiety as predictors of outcome after myocardial infarction. Psychosom Med. 2000;62:212-219.

62. Strik JJ, Denollet J, Lousberg R, Honig A. Comparing symptoms of depression and anxiety as predictors of cardiac events and increased health care consumption after myocardial infarction. J Am Coll Cardiol. 2003;42:1801-1807. 
63. Rutledge T, Linke SE, Krantz DS, et al. Comorbid depression and anxiety symptoms as predictors of cardiovascular events: results from the NHLBI-sponsored women's ischemia syndrome evaluation (WISE) study. Psychosom Med. 2009;71:958-964.

64. Morel-Kopp MC, McLean L, Chen Q, et al. The association of depression with platelet activation: evidence for a treatment effect. J Thromb Haemost. 2009;7:573-581.

65. Musselman DL, Marzec UM, Manatunga A, et al. Platelet reactivity in depressed patients treated with paroxetine: preliminary findings. Arch Gen Psychiatry. 2000;57:875-882.

66. Musselman DL, Tomer A, Manatunga AK, et al. Exaggerated platelet reactivity in major depression. Am J Psychiatry. 1996;153: 1313-1317.

67. Miyata K, Shimokawa H, Higo T, et al. Sarpogrelate, a selective 5-HT2A serotonergic receptor antagonist, inhibits serotonin-induced coronary artery spasm in a porcine model. $J$ Cardiovasc Pharmacol. 2000;35:294-301.

68. Vikenes K, Farstad M, Nordrehaug JE. Serotonin is associated with coronary artery disease and cardiac events. Circulation. 1999;100: 483-489.

69. Maurer-Spurej E, Pittendreigh C, Solomons K. The influence of selective serotonin reuptake inhibitors on human platelet serotonin. Thromb Haemost. 2004;91:119-128.

70. Schins A, Hamulyak K, Scharpe S, et al. Whole blood serotonin and platelet activation in depressed post-myocardial infarction patients. Life Sci. 2004;76:637-650.

71. Arora RC, Meltzer HY. Increased serotonin2 (5-HT2) receptor binding as measured by $3 \mathrm{H}$-lysergic acid diethylamide (3H-LSD) in the blood platelets of depressed patients. Life Sci. 1989;44:725-734.

72. Hrdina PD, Bakish D, Ravindran A, Chudzik J, Cavazzoni P, Lapierre YD. Platelet serotonergic indices in major depression: up-regulation of 5-HT2A receptors unchanged by antidepressant treatment. Psychiatry Res. 1997;66:73-85.

73. Nemeroff CB, Knight DL, Franks J, Craighead WE, Krishnan KR. Further studies on platelet serotonin transporter binding in depression. Am J Psychiatry. 1994;151:1623-1625.

74. Geiser F, Meier C, Wegener I, et al. Association between anxiety and factors of coagulation and fibrinolysis. Psychother Psychosom. 2008; 77:377-383.

75. Pivac N, Muck-Seler D, Jakovljevic M. Platelet 5-HT levels and hypothalamic-pituitary-adrenal axis activity in schizophrenic patients with positive and negative symptoms. Neuropsychobiology. 1997;36:19-21

76. Iny LJ, Pecknold J, Suranyi-Cadotte BE, et al. Studies of a neurochemical link between depression, anxiety, and stress from [3H]imipramine and $[3 \mathrm{H}]$ paroxetine binding on human platelets. Biol Psychiatry. 1994;36:281-291.

77. Plein H, Berk M. The platelet intracellular calcium response to serotonin and thrombin in patients with panic disorder. Eur Neuropsychopharmacol. 1999;9:107-110.

78. Muldoon MF, Herbert TB, Patterson SM, Kameneva M, Raible R, Manuck SB. Effects of acute psychological stress on serum lipid levels, hemoconcentration, and blood viscosity. Arch Intern Med. 1995; 155:615-620.

79. Levine SP, Towell BL, Suarez AM, Knieriem LK, Harris MM, George JN. Platelet activation and secretion associated with emotional stress. Circulation. 1985;71:1129-1134.

80. Libby P. Molecular bases of the acute coronary syndromes. Circulation. 1995;91:2844-2850.

81. Moyer CF, Sajuthi D, Tulli H, Williams JK. Synthesis of IL-1 alpha and IL-1 beta by arterial cells in atherosclerosis. Am J Pathol. 1991;138:951-960.

82. Heeschen C, Hamm CW, Bruemmer J, Simoons ML. Predictive value of $\mathrm{C}$-reactive protein and troponin $\mathrm{T}$ in patients with unstable angina: a comparative analysis. CAPTURE Investigators. Chimeric c7E3 AntiPlatelet Therapy in Unstable angina REfractory to standard treatment trial. J Am Coll Cardiol. 2000;35:1535-1542.
83. O’Brien SM, Scott LV, Dinan TG. Cytokines: abnormalities in major depression and implications for pharmacological treatment. Hum Psychopharmacol. 2004;19:397-403.

84. Pitsavos C, Panagiotakos DB, Papageorgiou C, Tsetsekou E, Soldatos C, Stefanadis C. Anxiety in relation to inflammation and coagulation markers, among healthy adults: the ATTICA study. Atherosclerosis. 2006;185:320-326.

85. von Kanel R, Begre S, Abbas CC, Saner H, Gander ML, Schmid JP. Inflammatory biomarkers in patients with posttraumatic stress disorder caused by myocardial infarction and the role of depressive symptoms. Neuroimmunomodulation. 2010;17:39-46.

86. von Kanel R, Hepp U, Kraemer B, et al. Evidence for low-grade systemic proinflammatory activity in patients with posttraumatic stress disorder. J Psychiatr Res. 2007;41:744-752.

87. Brennan AM, Fargnoli JL, Williams CJ, et al. Phobic anxiety is associated with higher serum concentrations of adipokines and cytokines in women with diabetes. Diabetes Care. 2009;32:926-931.

88. Bankier B, Barajas J, Martinez-Rumayor A, Januzzi JL. Association between C-reactive protein and generalized anxiety disorder in stable coronary heart disease patients. Eur Heart J. 2008;29:2212-2217.

89. Buccelletti E, Gilardi E, Scaini E, et al. Heart rate variability and myocardial infarction: systematic literature review and metanalysis. Eur Rev Med Pharmacol Sci. 2009;13:299-307.

90. Frenneaux MP. Autonomic changes in patients with heart failure and in post-myocardial infarction patients. Heart. 2004;90: $1248-1255$

91. Carney RM, Freedland KE. Depression and heart rate variability in patients with coronary heart disease. Cleve Clin J Med. 2009;76 Suppl 2:S13-17.

92. Carney RM, Blumenthal JA, Stein PK, et al. Depression, heart rate variability, and acute myocardial infarction. Circulation. 2001;104:2024-2028.

93. Stein PK, Carney RM, Freedland KE, et al. Severe depression is associated with markedly reduced heart rate variability in patients with stable coronary heart disease. J Psychosom Res. 2000;48:493500 .

94. Kawachi I, Sparrow D, Vokonas PS, Weiss ST. Decreased heart rate variability in men with phobic anxiety (data from the Normative Aging Study). Am J Cardiol. 1995;75:882-885.

95. Francis JL, Weinstein AA, Krantz DS, et al. Association between symptoms of depression and anxiety with heart rate variability in patients with implantable cardioverter defibrillators. Psychosom Med. 2009;71:821-827.

96. Lett HS, Blumenthal JA, Babyak MA, et al. Depression as a risk factor for coronary artery disease: evidence, mechanisms, and treatment. Psychosom Med. 2004;66:305-315.

97. Ressler KJ, Nemeroff CB. Role of serotonergic and noradrenergic systems in the pathophysiology of depression and anxiety disorders. Depress Anxiety. 2000;12 Suppl 1:2-19.

98. Roth WT, Doberenz S, Dietel A, et al. Sympathetic activation in broadly defined generalized anxiety disorder. J Psychiatr Res. 2008;42:205212 .

99. Thayer JF, Friedman BH, Borkovec TD. Autonomic characteristics of generalized anxiety disorder and worry. Biol Psychiatry. 1996;39: 255-266.

100. Hoehn-Saric R, McLeod DR, Funderburk F, Kowalski P. Somatic symptoms and physiologic responses in generalized anxiety disorder and panic disorder: an ambulatory monitor study. Arch Gen Psychiatry. 2004;61:913-921.

101. de Jager J, Dekker JM, Kooy A, et al. Endothelial dysfunction and low-grade inflammation explain much of the excess cardiovascular mortality in individuals with type 2 diabetes: the Hoorn Study. Arterioscler Thromb Vasc Biol. 2006;26:1086-1093.

102. Fischer D, Rossa S, Landmesser U, et al. Endothelial dysfunction in patients with chronic heart failure is independently associated with increased incidence of hospitalization, cardiac transplantation, or death. Eur Heart J. 2005;26:65-69. 
103. Katz SD, Hryniewicz K, Hriljac I, et al. Vascular endothelial dysfunction and mortality risk in patients with chronic heart failure. Circulation. 2005;111:310-314.

104. Pizzi C, Manzoli L, Mancini S, Costa GM. Analysis of potential predictors of depression among coronary heart disease risk factors including heart rate variability, markers of inflammation, and endothelial function. Eur Heart J. 2008;29:1110-1117.

105. Sherwood A, Hinderliter AL, Watkins LL, Waugh RA, Blumenthal JA. Impaired endothelial function in coronary heart disease patients with depressive symptomatology. J Am Coll Cardiol. 2005;46:656-659.

106. Harris KF, Matthews KA, Sutton-Tyrrell K, Kuller LH. Associations between psychological traits and endothelial function in postmenopausal women. Psychosom Med. 2003;65:402-409.

107. Narita K, Murata T, Hamada T, et al. Association between trait anxiety and endothelial function observed in elderly males but not in young males. Int Psychogeriatr. 2007;19:947-954.

108. Narita K, Murata T, Hamada T, et al. Interactions among higher trait anxiety, sympathetic activity, and endothelial function in the elderly. J Psychiatr Res. 2007;41:418-427.

109. Huffman JC, Smith FA, Fricchione GL, Januzzi JL, Nadelman S, Pirl WF. Depression and failure of cholesterol lowering after acute myocardial infarction. Prim Care Companion J Clin Psychiatry. 2010;12:e1-e6.

110. Ziegelstein RC, Fauerbach JA, Stevens SS, Romanelli J, Richter DP, Bush DE. Patients with depression are less likely to follow recommendations to reduce cardiac risk during recovery from a myocardial infarction. Arch Intern Med. 2000;160:1818-1823.

111. Whooley MA, de Jonge P, Vittinghoff E, et al. Depressive symptoms, health behaviors, and risk of cardiovascular events in patients with coronary heart disease. JAMA. 2008;300:2379-2388.

112. Kuhl EA, Fauerbach JA, Bush DE, Ziegelstein RC. Relation of anxiety and adherence to risk-reducing recommendations following myocardial infarction. Am J Cardiol. 2009;103:1629-1634.

113. Lane D, Carroll D, Ring C, Beevers DG, Lip GY. Predictors of attendance at cardiac rehabilitation after myocardial infarction. J Psychosom Res. 2001;51:497-501.

114. Ades PA, Waldmann ML, McCann WJ, Weaver SO. Predictors of cardiac rehabilitation participation in older coronary patients. Arch Intern Med. 1992;152:1033-1035.

115. McGrady A, McGinnis R, Badenhop D, Bentle M, Rajput M. Effects of depression and anxiety on adherence to cardiac rehabilitation. J Cardiopulm Rehabil Prev. 2009;29:358-364.

116. Casey E, Hughes JW, Waechter D, Josephson R, Rosneck J. Depression predicts failure to complete phase-II cardiac rehabilitation. J Behav Med. 2008;31:421-431.

117. Glassman AH, Roose SP. Risks of antidepressants in the elderly: tricyclic antidepressants and arrhythmia-revising risks. Gerontology. 1994;40 Suppl 1:15-20.

118. Cohen HW, Gibson G, Alderman MH. Excess risk of myocardial infarction in patients treated with antidepressant medications: association with use of tricyclic agents. Am J Med. 2000;108:2-8.

119. Shapiro PA, Lesperance F, Frasure-Smith N, et al. An open-label preliminary trial of sertraline for treatment of major depression after acute myocardial infarction (the SADHAT Trial). Sertraline Anti-Depressant Heart Attack Trial. Am Heart J. 1999;137: 1100-1106.

120. Strik JJ, Honig A, Lousberg R, et al. Efficacy and safety of fluoxetine in the treatment of patients with major depression after first myocardial infarction: findings from a double-blind, placebo-controlled trial. Psychosom Med. 2000;62:783-789.

121. Taylor CB, Youngblood ME, Catellier D, et al. Effects of antidepressant medication on morbidity and mortality in depressed patients after myocardial infarction. Arch Gen Psychiatry. 2005;62:792-798.

122. Pollock BG, Laghrissi-Thode F, Wagner WR. Evaluation of platelet activation in depressed patients with ischemic heart disease after paroxetine or nortriptyline treatment. J Clin Psychopharmacol. 2000;20:137-140.
123. Serebruany VL, Glassman AH, Malinin AI, et al. Platelet/endothelial biomarkers in depressed patients treated with the selective serotonin reuptake inhibitor sertraline after acute coronary events: the Sertraline AntiDepressant Heart Attack Randomized Trial (SADHART) Platelet Substudy. Circulation. 2003;108:939-944.

124. Honig A, Kuyper AM, Schene AH, et al. Treatment of post-myocardial infarction depressive disorder: a randomized, placebo-controlled trial with mirtazapine. Psychosom Med. 2007;69:606-613.

125. van Melle JP, de Jonge P, Honig A, et al. Effects of antidepressant treatment following myocardial infarction. Br J Psychiatry. 2007;190:460-466.

126. Rigotti NA, Thorndike AN, Regan S, et al. Bupropion for smokers hospitalized with acute cardiovascular disease. Am J Med. 2006;119: 1080-1087.

127. Thase ME. Effects of venlafaxine on blood pressure: a meta-analysis of original data from 3744 depressed patients. J Clin Psychiatry. 1998;59:502-508.

128. Cote P, Campeau L, Bourassa MG. Therapeutic implications of diazepam in patients with elevated left ventricular filling pressure. Am Heart J. 1976;91:747-751.

129. Cote P, Noble J, Bourassa MG. Systemic vasodilatation following diazepam after combined sympathetic and parasympathetic blockade in patients with coronary heart disease. Cathet Cardiovasc Diagn. 1976;2:369-380.

130. Arbanas G, Arbanas D, Dujam K. Adverse effects of benzodiazepines in psychiatric outpatients. Psychiatr Danub. 2009;21:103-107.

131. Wheatley D. The value of anti-anxiety drugs in the management of cardiac disease. Acta Med Scand Suppl. 1982;660:219-230.

132. Norton PJ, Price EC. A meta-analytic review of adult cognitivebehavioral treatment outcome across the anxiety disorders. JNerv Ment Dis. 2007;195:521-531.

133. Linden W, Phillips MJ, Leclerc J. Psychological treatment of cardiac patients: a meta-analysis. Eur Heart J. 2007;28:2972-2984.

134. Blumenthal JA, Babyak MA, Moore KA, et al. Effects of exercise training on older patients with major depression. Arch Intern Med. 1999;159:2349-2356.

135. De Moor MH, Beem AL, Stubbe JH, Boomsma DI, De Geus EJ. Regular exercise, anxiety, depression and personality: a populationbased study. Prev Med. 2006;42:273-279.

136. Blumenthal JA, Babyak MA, Doraiswamy PM, et al. Exercise and pharmacotherapy in the treatment of major depressive disorder. Psychosom Med. 2007;69:587-596.

137. Blumenthal JA, Sherwood A, Gullette EC, et al. Exercise and weight loss reduce blood pressure in men and women with mild hypertension: effects on cardiovascular, metabolic, and hemodynamic functioning. Arch Intern Med. 2000;160:1947-1958.

138. Huffman JC, Stern TA. Neuropsychiatric consequences of cardiovascular medications. Dialogues Clin Neurosci. 2007;9: 29-45.

139. Buydens-Branchey L, Branchey M, Hudson J, Fergeson P. Low HDL cholesterol, aggression and altered central serotonergic activity. Psychiatry Res. 2000;93:93-102.

140. Neaton JD, Blackburn H, Jacobs D, et al. Serum cholesterol level and mortality findings for men screened in the Multiple Risk Factor Intervention Trial. Multiple Risk Factor Intervention Trial Research Group. Arch Intern Med. 1992;152:1490-1500.

141. Shin JY, Suls J, Martin R. Are cholesterol and depression inversely related? A meta-analysis of the association between two cardiac risk factors. Ann Behav Med. 2008;36:33-43.

142. Sullivan PF, Joyce PR, Bulik CM, Mulder RT, Oakley-Browne M. Total cholesterol and suicidality in depression. Biol Psychiatry. 1994;36:472-477.

143. Manfredini R, Caracciolo S, Salmi R, Boari B, Tomelli A, Gallerani M. The association of low serum cholesterol with depression and suicidal behaviours: new hypotheses for the missing link. J Int Med Res. 2000;28:247-257. 
144. HMG-CoA reductase inhibitors for hypercholesterolemia. $N$ Engl J Med. 1988;319:1222-1223.

145. Davidson MH, Stein EA, Hunninghake DB, et al. Lipid-altering efficacy and safety of simvastatin $80 \mathrm{mg} /$ day: worldwide long-term experience in patients with hypercholesterolemia. Nutr Metab Cardiovasc Dis. 2000;10:253-262.

146. Hallas J. Evidence of depression provoked by cardiovascular medication: a prescription sequence symmetry analysis. Epidemiology. 1996;7:478-484.

147. Thiessen BQ, Wallace SM, Blackburn JL, Wilson TW, Bergman U. Increased prescribing of antidepressants subsequent to beta-blocker therapy. Arch Intern Med. 1990;150:2286-2290.

148. Perez-Stable EJ, Halliday R, Gardiner PS, et al. The effects of propranolol on cognitive function and quality of life: a randomized trial among patients with diastolic hypertension. Am J Med. 2000;108: 359-365.

149. Stoudemire A, Brown JT, Harris RT, et al. Propranolol and depression: a reevaluation based on a pilot clinical trial. Psychiatr Med. 1984; 2:211-218.

150. Ko DT, Hebert PR, Coffey CS, Sedrakyan A, Curtis JP, Krumholz HM. Beta-blocker therapy and symptoms of depression, fatigue, and sexual dysfunction. JAMA. 2002;288:351-357.
151. Fleminger S, Greenwood RJ, Oliver DL. Pharmacological management for agitation and aggression in people with acquired brain injury. Cochrane Database Syst Rev. 2003:CD003299.

152. Vaiva G, Ducrocq F, Jezequel K, et al. Immediate treatment with propranolol decreases posttraumatic stress disorder two months after trauma. Biol Psychiatry. 2003;54:947-949.

153. Katon WJ, Von Korff M, Lin EH, et al. The Pathways Study: a randomized trial of collaborative care in patients with diabetes and depression. Arch Gen Psychiatry. 2004;61:1042-1049.

154. Simon GE, Katon WJ, Lin EH, et al. Cost-effectiveness of systematic depression treatment among people with diabetes mellitus. Arch Gen Psychiatry. 2007;64:65-72.

155. Unutzer J, Katon W, Callahan CM, et al. Collaborative care management of late-life depression in the primary care setting: a randomized controlled trial. JAMA. 2002;288:2836-2845.

156. Unutzer J, Katon WJ, Fan MY, et al. Long-term cost effects of collaborative care for late-life depression. Am J Manag Care. 2008;14:95-100.

157. Rollman BL, Belnap BH, LeMenager MS, et al. Telephone-delivered collaborative care for treating post-CABG depression: a randomized controlled trial. JAMA. 2009;302:2095-2103.

\section{Publish your work in this journal}

Neuropsychiatric Disease and Treatment is an international, peerreviewed journal of clinical therapeutics and pharmacology focusing on concise rapid reporting of clinical or pre-clinical studies on a range of neuropsychiatric and neurological disorders. This journal is indexed on PubMed Central, the 'PsycINFO' database and CAS, and is the official journal of The International Neuropsychiatric Association (INA). The manuscript management system is completely online and includes a very quick and fair peer-review system, which is all easy to use. Visit http://www.dovepress.com/testimonials.php to read real quotes from published authors. 